\title{
DESENVOLVIMENTO LARVAL DE CYRTOGRAPSUS ANGULATUS DANA (CRUSTACEA, DECAPODA, GRAPSIDAE) EM LABORATÓRIO
}

\author{
Paulo Juarez Rieger ${ }^{1}$ \\ Rony Roberto Ramos Vieira ${ }^{1,2}$
}

\begin{abstract}
LARVAL DEVELOPMENT OF CYRTOGR.4PSUS ANGUL.4TUS DANA (CRUSTACEA, DECAPODA, GRAPSIDAE) IN THE LABORATORY. The larval development of Cyrtograpsus angulatus Dana, 1851 was studied in laboratory through eggs hatched from ovigerous females collected in mole of Rio Grande, Rio Grande, State of Rio Grande do Sul, Brazil. Three experiments (A, B, C) were carried out involving 250 larvae, derived from three ovigerous females. The experiments $\mathrm{A}$ and $\mathrm{B}$, were carried in a climatically box with temperature among 22 and $25^{\circ} \mathrm{C}$, and salinity among 32 and $34 \%$. The experiment $\mathrm{C}$ in a room without controlled temperature, in a constant salinity of $30 \%$. The larvae were maintained individually and food consisted of rotifers Brachionus plicatillis Müller, 1786 and microscope algae Tetraselmis sp. The development of $C$. angulatus Dana, 1851 comprises five stages of zoea and one megalope. The main morphological characters that allow the identification of the first stages of $C$. angulatus, are analyzed with respect to the other Brazilian species of the family Grapsidae. KEY WORDS. Crustacea, Decapoda, Grapsidae, Cyrtograpsus angulatus, larval development
\end{abstract}

Os trabalhos sobre os Grapsidae que ocorrem no Brasil restringem-se basicamente às descrições e distribuições geográficas das espécies, entre os quais merecem destaque os trabalhos de RATHBUn (1918), HolthUIS (1959), FAUSTOFilho $(1966,1967,1968)$, Coelho (1971), Coelho \& Ramos (1972), GuINoT (1978), Coelho et al. (1980); Williams (1984) e Melo (1996).

A família Grapsidae está constituída por quatro sub-famílias: Grapsinae, Sesarminae, Varuninae e Plagusiinae, sendo que destas são encontradas na região

Sudeste do Brasil representantes das sub-famílias Grapsinae, Sesarminae e Varuninae. Segundo MELo (1996) estas encontram-se representadas por 15 gêneros e 22 espécies. Foram encontradas nos Molhes da Barra e adjacências (marisma) de Rio Grande, Rio Grande do Sul, representantes das três sub-famílias compostas por quatro gêneros e quatro espécies assim distribuídas: Pachygrapsus transversus Gibber, 1850; Metasesarma rubripes Rathbun, 1897; Chasmagnathus gramulata Dana, 1851; Cyrtograpsus angulatus Dana, 1851.

1) Laboratório de Zoologia Crustacea Decapoda, Departamento de Ciências Morfológicas e Biológicas, Fundação Universidade do Rio Grande. Caixa Postal 474, 96201-900 Rio Grande, Rio Grande do Sul, Brasil.

2) Bolsista de Iniciação Científica (CNPq). 
No que diz respeito à morfologia e ao desenvolvimento das formas larvais regionais, foram publicados os trabalhos das seguintes espécies: Chasmagnathus granulata por BOSCHI et al. (1967), Metasesarma rubripes por DIAZ \& EWALD (1968) e Cyrtograpsus altimanus por SCELzo \& BASTIDA (1978). No tocante ao desenvolvimento larval são desconhecidos: Cyrtograpsus angulatus e Pachygrapsus transversus, fato que justifica a relevância do presente trabalho.

Levando-se em conta as considerações acima citadas e o propósito de contribuir para um melhor conhecimento das formas larvais da fauna braquiurológica do litoral Sul do Estado do Rio Grande do Sul, este trabalho tem por objetivos principais o estudo, sob condições de laboratório do desenvolvimento larval de Cyrtograpsus angulatus. Neste particular, são mencionados os tratamentos oferecidos as larvas, os intervalos de tempo entre as ecdises e as porcentagens de sobrevivência nas diferentes fases do desenvolvimento.

Estabelecer os principais caracteres morfológicos que permitam, a nível larval, as identificações de Cyrtograpsus angulatus e apresentar os principais caracteres morfológicos das zoeas da sub-família Varuninae e Sesarminae, que permitam as identificações dos gêneros que ocorrem no litoral Sul do Estado do Rio Grande do Sul.

\section{MATERIAL E MÉTODOS}

As fêmeas ovígeras de Cyrtograpsus angulatus foram coletadas nos molhes da barra de Rio Grande, rio Grande do Sul, na região conhecida como prainha.

$\mathrm{O}$ transporte das fêmeas ovígeras para o laboratório foi efetuado em caixa de isopor, com uma pequena quantidade de água do local de coleta. No laboratório, as fêmeas foram isoladas em aquários com capacidade para 20 litros de água, com aeração contínua, até a eclosão das larvas (Zoea I).

Após a eclosão, as larvas foram atraídas por um foco de luz e com um conta gotas foram individualizadas em recipientes de plástico com capacidade para $150 \mathrm{ml}$, com $20 \mathrm{ml}$ de água do mar filtrada em rede de 96 micra.

Foram realizados três experimentos denominados (A, B e C), envolvendo um total de 250 larvas oriundas de três fềmeas ovígeras. No experimento $\mathrm{A}$, foram individualizadas 50 larvas; no B, 100 larvas e no experimento C, 100 larvas. Os experimentos $\mathrm{A}$ e $\mathrm{B}$ foram realizados em água do mar com salinidade variando entre 32 e $34 \%$ e o experimento C, em $30 \%$.

Os experimentos $\mathrm{A}$ e $\mathrm{B}$ foram realizados no interior de uma caixa da isopor com as seguintes medidas: $50 \mathrm{~cm}$ de largura; $70 \mathrm{~cm}$ de comprimento e $40 \mathrm{~cm}$ de altura. Estes somente eram retirados por ocasião das observações diárias. Uma vez que estes experimentos foram realizados no auge do verão (experimento A, eclosão 17/02; experimento B, 19/02), eram acrescentados copos com gelo com que a temperatura no interior da caixa foi mantida em $23,5 \pm 2^{\circ} \mathrm{C}$. O experimento $\mathrm{C}$ foi realizado fora da caixa de isopor com temperatura de $22 \pm 2^{\circ} \mathrm{C}$ e a eclosão ocorreu em 28/09.

Houve um acompanhamento diário dos experimentos para constatação da mortalidade e verificação da ocorrência de ecdises com a conseqüente determinação 
das mudanças de estágios. A seguir procedeu-se a troca de água dos recipientes e a introdução de alimento constituído de algas Tetraselmis sp. e rotíferos Brachionus plicatillis Müller, 1786 nos primeiros estágios e náuplius de Artemia sp., a partir do terceiro estágio na fase de zoea.

As larvas mortas e exúvias de cada estágio foram fixadas e preservadas em uma mistura de álcool etílico $96 \%$ e glicerina na proporção de 1:1.

As descrições morfológicas, as medidas e os desenhos foram efetuados com auxílio de um microscópio óptico comum, equipado com câmara clara à partir de exúvias e larvas preservadas.

$\mathrm{Na}$ apresentação dos resultados, tabelas e figuras, dos diferentes estágios, foram adotados os seguintes símbolos: Z-I - zoea do primeiro estágio; Z-II - zoea do segundo estágio; Z-III - zoea do terceiro estágio; Z-IV - zoea do quarto estágio; $\mathrm{Z}-\mathrm{V}$ - zoea do quinto estágio; M - estágio único da fase de megalopa. Os números entre parênteses significam uma ocorrência em menor freqüência. Foram analisados 10 indivíduos de cada estágio. As larvas e/ou suas exúvias encontram-se depositadas na coleção do Laboratório de Zoologia de Crustaceos Decapodes (DCMB) da Fundação Universidade do Rio Grande, lotes números 258 a 289.

A metodologia utilizada baseou-se em RIEGER \& HEBLING (1993) e RiEGER (1996). A terminologia adotada foi a de Rice (1980), Fransozo \& HEBLING (1986), Negreiros-Fransozo et al. (1989), Rodrigues \& Hebling (1989) e Rieger \& HEBLING (1993).

\section{RESULTADOS}

Distribuição geográfica de Cyrtograpsus angulatus: Atlântico sul ocidental: Brasil (Rio de Janeiro até o Rio Grande do Sul), Uruguai, Argentina (Patagônia) e Pacífico oriental: Peru e Chile (Melo 1996).

Pela análise dos resultados das coletas quinzenais, realizadas durante um ano, de C. angulatus, nos molhes da barra de Rio Grande e arredores, constatou-se a ocorrência de fêmeas ovígeras durante o período compreendido entre os meses de setembro e meados de abril. Em termos quantitativos, os resultados de todas as coletas são apresentados na tabela I. Em todas as coletas verificou-se que a porcentagem de fềmeas ovígeras é relativamente pequena em relação aos machos e fềmeas não ovígeras.

Para eclosão das larvas, em laboratório, os resultados mais viáveis foram obtidos a partir de fêmeas ovígeras com embriões em estágios mais avançados de desenvolvimento, caracterizados pela posse de olhos compostos bem pigmentados e facilmente observáveis através da membrana envoltória do ovo.

\section{Desenvolvimento Larval}

O desenvolvimento larval é constituído de cinco estágios na fase de zoea e um estágio na fase de megalopa. Das 50 larvas inicias do experimento $\mathrm{A}$, foram obtidas 35 megalopas, e destas 31 juvenis I; no experimento B, das 100 larvas, foram obtidas 68 megalopas e destas 66 juvenis I e no experimento C, das 100 larvas foram obtidas 60 megalopas e destas 48 juvenis I. 
Tabela I. Cyrtograpsus angulatus. Resultados das Coletas.

\begin{tabular}{lrrrrc}
\hline Local & Data & $\begin{array}{c}\text { Total } \\
\text { exemplares }\end{array}$ & Machos & Fêmeas & $\begin{array}{c}\text { Fêmeas } \\
\text { ovígera }\end{array}$ \\
\hline Molhes da Barra & $28 / 12$ & 15 & 5 & 8 & 2 \\
Molhes da Barra & $04 / 01$ & 8 & 6 & 1 & 1 \\
Molhes da Barra & $07 / 01$ & 26 & 12 & 10 & 4 \\
Molhes da Barra & $12 / 02$ & 12 & 5 & 4 & 3 \\
Prainha & $28 / 02$ & 24 & 14 & 9 & 1 \\
Prainha & $19 / 03$ & 8 & 2 & 4 & 2 \\
Prainha & $06 / 04$ & 9 & 4 & 2 & 3 \\
Prainha & $23 / 04$ & 0 & 0 & 0 & 0 \\
Prainha & $05 / 05$ & 0 & 0 & 0 & 0 \\
Ponte dos Franceses & $18 / 06$ & 0 & 0 & 0 & 0 \\
Molhes da Barra & $30 / 06$ & 0 & 0 & 0 & 0 \\
Ponte dos Franceses & $20 / 07$ & 0 & 0 & 0 & 0 \\
Prainha & $20 / 07$ & 0 & 0 & 0 & 0 \\
Prainha & $20 / 08$ & 0 & 0 & 0 & 0 \\
Prainha & $03 / 09$ & 10 & 3 & 6 & 1 \\
Prainha & $24 / 09$ & 6 & 3 & 2 & 1 \\
Prainha & $01 / 10$ & 19 & 8 & 10 & 1 \\
Prainha & $15 / 10$ & 0 & 0 & 0 & 0 \\
Prainha & $26 / 10$ & 5 & 2 & 2 & 1 \\
Prainha & $12 / 11$ & 1 & 1 & 0 & 0 \\
Prainha & $19 / 11$ & 6 & 4 & 1 & 1 \\
Prainha & $26 / 11$ & 0 & 0 & 0 & 0 \\
Prainha & $03 / 12$ & 2 & 1 & 1 & 0 \\
Prainha & $10 / 12$ & 25 & 13 & 11 & 1 \\
\hline
\end{tabular}

Os resultados das durações e sobrevivência dos estágios da fase larval, obtidos nos cultivos A, B e C são apresentados na tabela II e nas figuras 1 a 3, respectivamente.

\section{Morfologia dos Estágios Larvais}

\section{ZOEA I}

Carapaça (Fig. 4-I) - globosa com uma par de espinhos laterais, um espinho dorsal e um rostral, como nos demais estágios de zoea. Os olhos são sésseis. Abdome (Fig. 5-I) - pentasegmentado com um par de espinhos laterais medianos no segundo segmento e um par de espinhos laterais medianos no terceiro segmento. O telso (Fig. 5-I) com pequenos espinhos na metade distal de cada furca e três pares de cerdas plumosas $(3+3)$ em sua margem interna.

Antênula (Fig. 6-I) - não segmentada, cônica, com três estetos distais e uma cerda simples sub-distal.

Antena (Fig. 7-I) - com protopodito afilado, provido de um processo espinhoso com duas fileiras laterais de pequenos espinhos à partir de sua metade distal, a qual coincide com a região do exopodito que apresenta as duas cerdas laterais lisas. Exopodito com comprimento equivalente à metade do protopodito, com uma cerda lisa na margem interna e uma na margem externa e uma porção afilada distal, cujo comprimento é equivalente a $2 / 5$ do exopodito. 


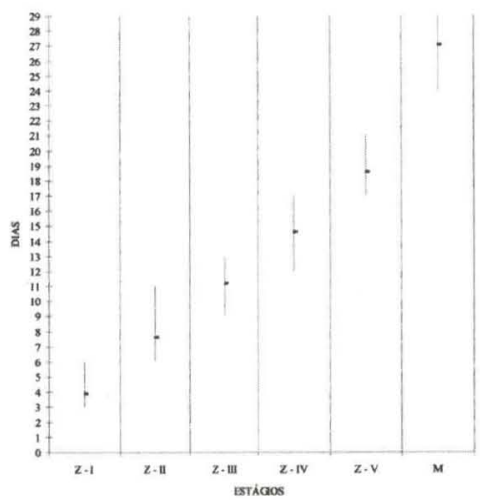

Fig. 1. Cyrtograpsus angulatus. Duração (acumulada) mínima, média e máxima dos estágios do desenvolvimento larval, em salinidades de 32 e $34 \%$ e temperatura de $23,5 \pm 2^{\circ} \mathrm{C}$.

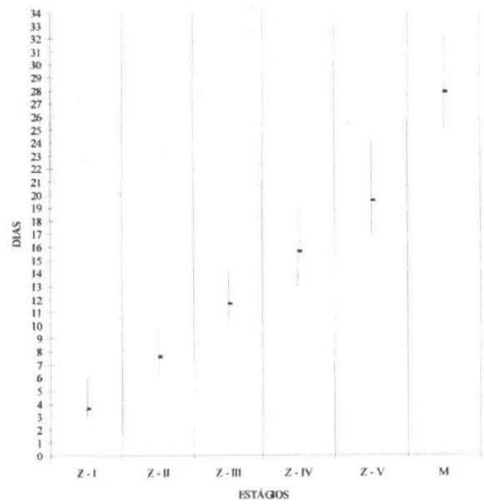

Fig. 2. Cyrtograpsus angulatus. Duração (acumulada) minima, máxıma e média dos estágios do desenvolvimento larval, em salinidades de 32 e $34 \%$ e temperatura de $23,5 \pm 2^{\circ} \mathrm{C}$.

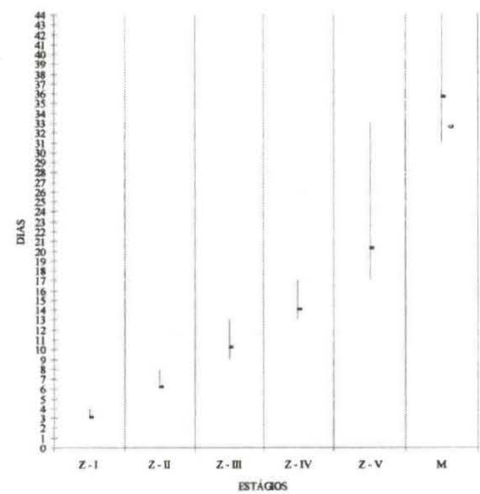

Fig. 3. Cyrtograpsus angulatus. Duração (acumulada) minima, máxima e média dos estágios do desenvolvimento larval, em salinidade de $30 \%$ e temperatura de $22 \pm 2^{\circ} \mathrm{C}$. 
Tabela II. Cyrtograpsus angulatus. Duração e sobrevivência dos estágios larvais, a partir da eclosão. (X) Duração média acumulada (em dias); (D e D') duração mínima e máxima; ( $n$ ) número de indivíduos vivos; $(\dagger)$ número de indivíduos mortos; $(\mathrm{S} \%)$ porcentagem de sobrevivência. Cultivos: " $A$ " com $n=50$, " $B$ " com $n=100$ e "C" com $n=100$ zoeas.

\begin{tabular}{ccccccc}
\hline Cultivo A & Zoea I & Zoea II & Zoea III & Zoea IV & Zoea V & M \\
\hline X & 3,9 & 7,6 & 11,2 & 14,6 & 18,6 & 27,0 \\
D & 3 & 6 & 9 & 12 & 17 & 24 \\
D' & 6 & 11 & 13 & 17 & 21 & 29 \\
n & 46 & 39 & 37 & 36 & 35 & 31 \\
$(\dagger)$ & 4 & 7 & 2 & 1 & 1 & 4 \\
S\% & 92 & 78 & 74 & 72 & 70 & 62 \\
\hline Cultivo B & & & & & & \\
X & 3,6 & 7,6 & 11,6 & 15,6 & 19,5 & 27,8 \\
D & 3 & 6 & 10 & 13 & 17 & 25 \\
D' & 6 & 10 & 14 & 19 & 24 & 32 \\
n & 91 & 76 & 73 & 69 & 68 & 66 \\
$(\dagger)$ & 9 & 15 & 3 & 4 & 1 & 2 \\
S\% & 91 & 76 & 73 & 69 & 68 & 66 \\
\hline Cultivo C & & & & & & \\
X & 3,1 & 6,2 & 10,2 & 14,0 & 20,2 & 35,6 \\
D & 3 & 6 & 9 & 13 & 17 & 31 \\
D' & 4 & 8 & 13 & 17 & 33 & 44 \\
n & 85 & 81 & 68 & 66 & 60 & 48 \\
$(\dagger)$ & 15 & 4 & 13 & 2 & 6 & 12 \\
S\% & 85 & 81 & 68 & 66 & 60 & 48 \\
\hline
\end{tabular}

Mandíbula (Fig. 8-I) - processo incisivo com quatro proeminências dentiformes, de tamanhos equivalentes. Processo molar provido de pequenos dentes.

Maxílula (Fig. 9-I) - endopodito bissegmentado com uma cerda plumosa no segmento proximal, quatro cerdas plumosas terminais e uma sub-terminal no segmento distal. Endito basal com cinco cerdas plumosas. Endito coxal com cinco cerdas plumosas. Protopodito não apresenta cerdas.

Maxila (Fig. 10-I) - endopodito bilobado com duas cerdas plumosas distais em cada lobo. Endito basal com 4(5) cerdas plumosas no lobo proximal e 3(4) cerdas plumosas no lobo distal. Endito coxal com três cerdas plumosas no lobo proximal e duas no lobo distal. Exopodito (escafognatito) com quatro cerdas plumosas marginais e uma porção afilada, revestida por pequenas cerdas lisas.

Primeiro maxilípede (Fig. 11-I) - basipodito com 10 cerdas plumosas. Endopodito pentasegmentado com 2, 2, 1, 2 e 5 cerdas plumosas do segmento proximal para o distal. Exopodito bissegmentado com quatro cerdas plumosas natatórias no segmento distal.

Segundo maxilípede (Fig. 12-I) - basipodito com quatro cerdas plumosas. Endopodito trissegmentado com 0,1 e 6 cerdas plumosas do segmento proximal para o distal. Exopodito bissegmentado, com quatro cerdas plumosas natatórias no segmento distal. 


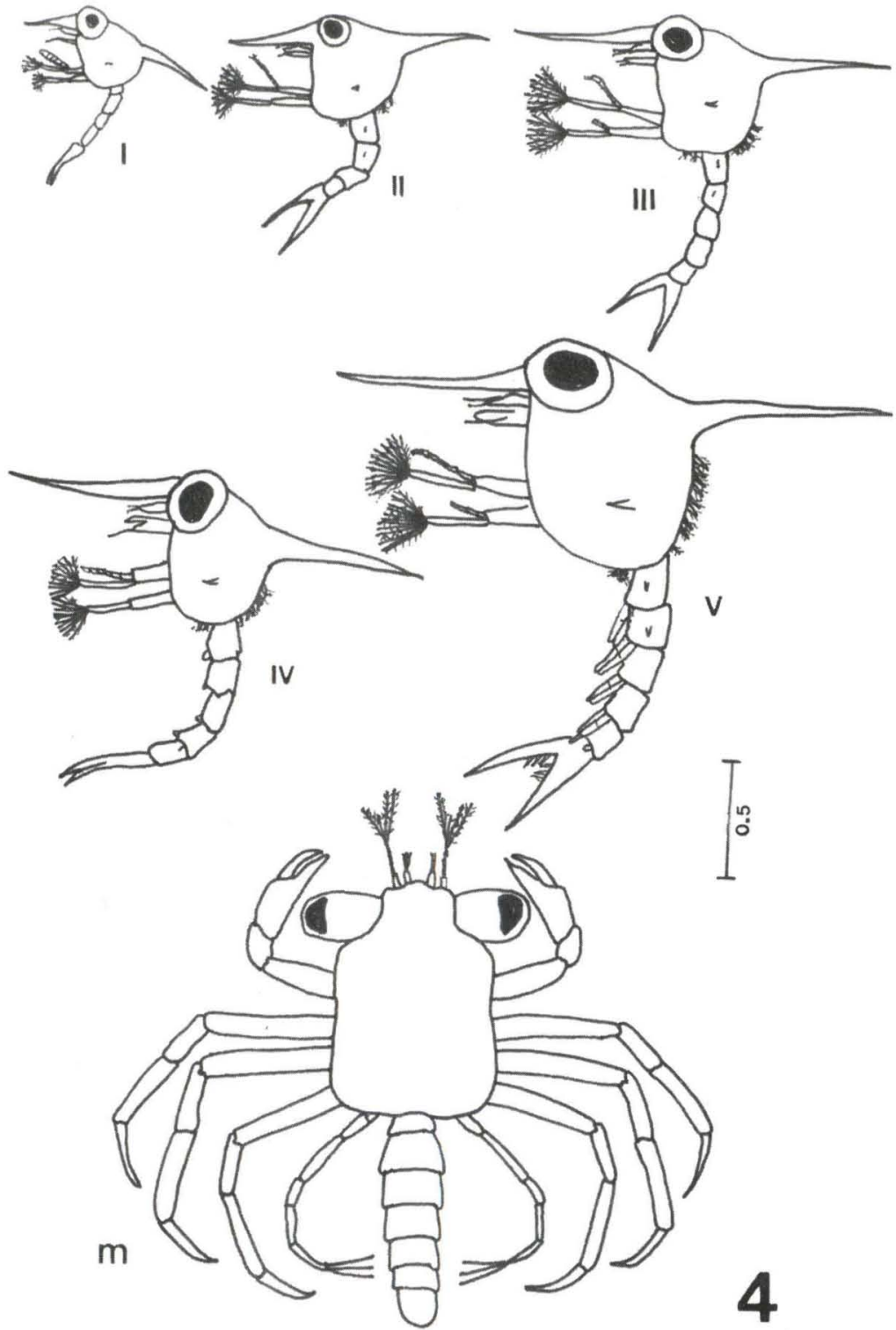

Fig. 4. Cyrtograpsus angulatus. (I-V) Estágio de zoea, vista lateral; $(\mathrm{m})$ vista dorsal do estágio de megalopa. Escala em milimetros.

\section{ZOEA II}

Carapaça (Fig. 4-II) - apresenta três cerdas plumosas dorsolaterais. Os olhos são ligeiramente pedunculados. Abdome (Fig. 5-II) e telso (Fig. 5-II) semelhantes ao estágio anterior. 

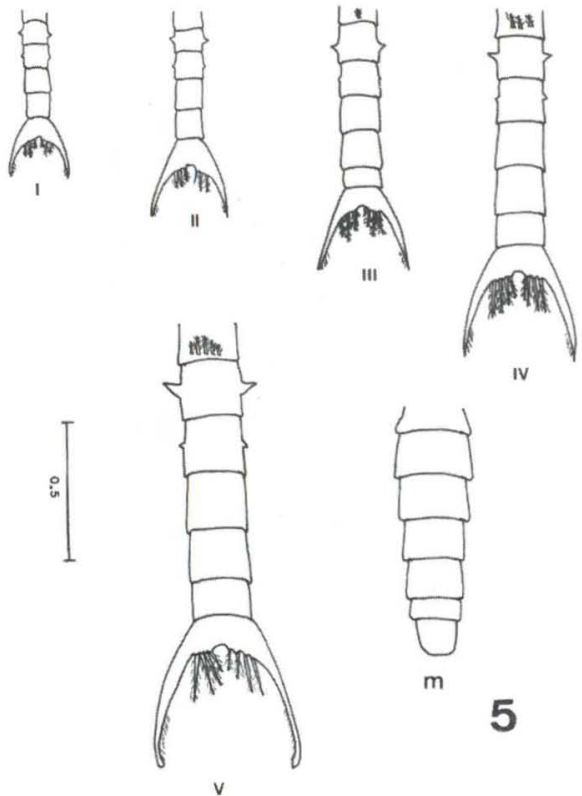

IV

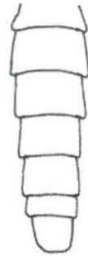

m

5

Fig. 5. Cyrtograpsus angulatus, vista dorsal do abdome. (I-V) estágio de zoea, (m) Megalopa. Escala em milimetros.
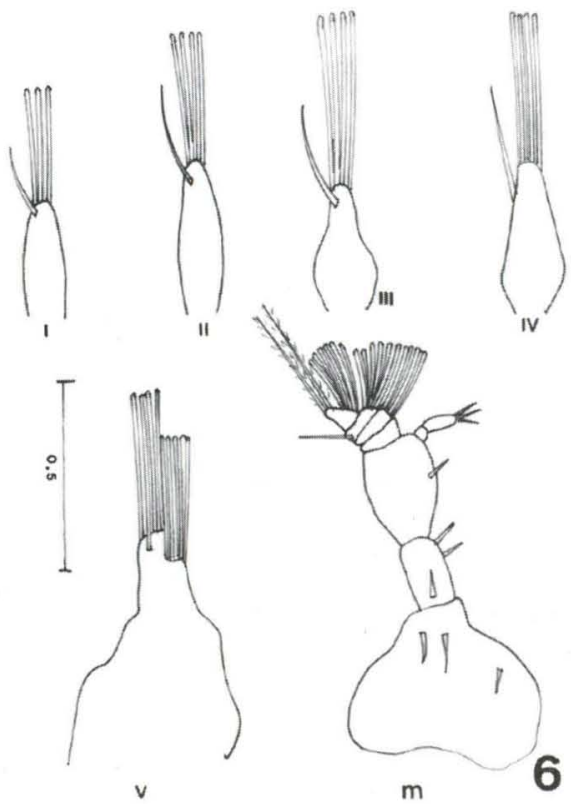

m

Fig. 6. Cyrtograpsus angulatus, antênula. (I-V) Estágio de zoea, $(\mathrm{m})$ megalopa. Escala em milimetros. 

sub-distal.

Antênula (Fig. 6-II) - com 4(5) estetos na região distal e uma cerda simples

Antena (Fig. 7-II) - protopodito com duas fileiras laterais de espinhos a partir de sua metade distal. Exopodito com duas cerdas laterais lisas e com uma porção distal afilada com comprimento equivalente a $3 / 7$ do comprimento do exopodito.

Mandíbula (Fig. 8-II) - processo incisivo com cinco projeções dentiformes. Processo molar semelhante ao estágio anterior.

Maxílula (Fig. 9-II) - endopodito bissegmentado com uma cerda plumosa no segmento proximal, quatro cerdas plumosas terminais e uma sub-terminal no segmento distal. Endito basal com sete cerdas plumosas e endito coxal com cinco cerdas plumosas. Protopodito com uma cerda plumosa.

Maxila (Fig. 10-II) - endopodito semelhante ao estágio anterior. Endito basal com quatro cerdas plumosas terminais no lobo distal e cinco no proximal. Endito coxal com três cerdas plumosas terminais no lobo distal e três no proximal. Exopodito com oito cerdas plumosas marginais.

Primeiro maxilípede (Fig. 11-II) - basipodito e endopodito semelhantes aos do estágio anterior, com o mesmo número de cerdas. Exopodito bissegmentado com seis cerdas plumosas natatórias.

Segundo maxilípede (Fig. 12-II) - basipodito e endopodito semelhantes aos do estágio anterior com o mesmo número de cerdas. Exopodito com seis cerdas plumosas natatórias distais.

ZOEA III

Carapaça (Fig. 4-III) - apresenta seis cerdas plumosas dorsolaterais. Os olhos são pedunculados. Abdome (Fig. 5-III) com uma cerda dorsal plumosa no primeiro segmento e apresenta o sexto segmento individualizado. O telso (Fig. 5-III) é semelhante ao estágio anterior, mas com quatro pares de cerdas plumosas $(4+4)$ em sua margem interna. sub-distal.

Antênula (Fig. 6-III) - com 4(5) estetos na região distal e uma cerda simples

Antena (Fig. 7-III) - semelhante ao estágio anterior, mas com início de diferenciação do endopodito, na forma de um pequeno bulbo. A porção afilada do protopodito apresenta os espinhos da margem interna maiores, diferenciados em relação aos da externa. Exopodito com duas cerdas laterais, sendo que o da margem interna apresenta-se reduzido enquanto que o da margem externa apresenta-se mais desenvolvido. Porção afilada distal do exopodito com comprimento equivalente a metade do exopodito.

Mandíbula (Fig. 8-III) - processo incisivo com cinco proeminências dentiformes. Processo molar com quatro cristas providas de pequenas saliências irregulares.

Maxílula (Fig. 9-III) - endopodito bissegmentado com uma cerda plumosa no segmento proximal, quatro cerdas plumosas terminais e uma sub-terminal no segmento distal. Endito basal com sete cerdas plumosas e endito coxal com cinco cerdas plumosas. Protopodito semelhante ao estágio anterior. 

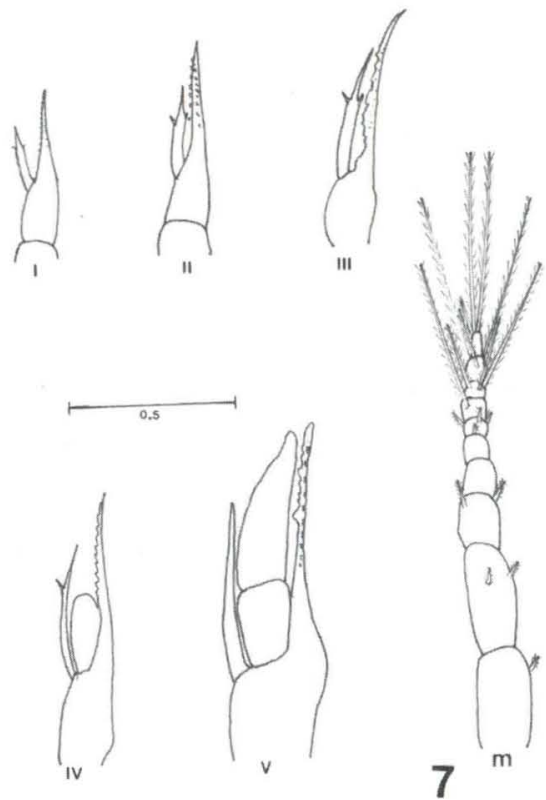

Fig. 7. Cyrtograpsus angulatus, antena. (I-V) Estágio de zoea, (m) megalopa. Escala em milímetros.
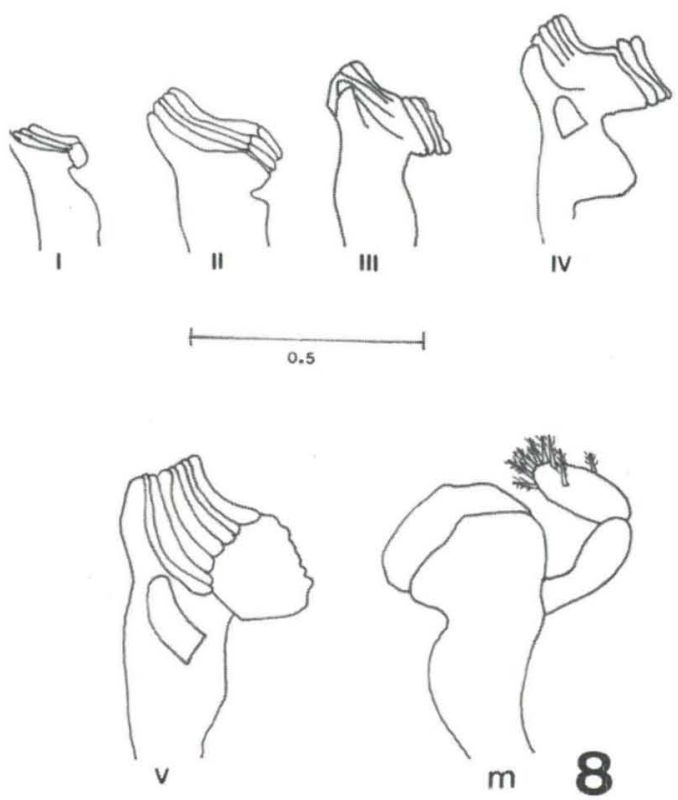

Fig. 8. Cyrtograpsus angulatus, mandibula. (I-V) Estágio de zoea, (m) megalopa. Escala em milimetros. 
Maxila (Fig. 10-III) - endopodito semelhante ao estágio anterior. Endito basal com 4(5) cerdas plumosas no lobo proximal e quatro no lobo distal. Endito coxal com 3(4) cerdas plumosas no lobo proximal e três no lobo distal. Exopodito com 13 cerdas plumosas marginais.

Primeiro maxilípede (Fig. 11-III) - basipodito semelhante ao estágio anterior. Endopodito com 2, 2, 2, 2, 6 cerdas plumosas do segmento proximal para o distal. Exopodito com oito cerdas plumosas natatórias distais.

Segundo maxilípede (fig. 12-III) - basipodito e endopodito semelhante ao estágio anterior com o mesmo número de cerdas. Exopodito com oito cerdas plumosas natatórias distais.

\section{ZOEA IV}

Carapaça (Fig. 4-IV) - apresenta oito cerdas plumosas dorsolaterais. Abdome (Fig. 5-IV) com três cerdas dorsais plumosas no primeiro segmento, rudimentos de pleópodos começam a aparecer em forma de um pequeno bulbo nos segmentos 2, 3, 4 e 5. O telso (Fig. 5-IV) é semelhante ao estágio anterior.

Antênula (Fig. 6-IV) - com quatro estetos na região distal uma cerda simples e um esteto sub-distal.

Antena (Fig. 7-IV) - processo espinhoso do protopodito com diferenciação mais acentuada com relação às fileiras de espinhos das margens interna e externa. Endopodito mais desenvolvido, com comprimento equivalente a $3 / 5$ do exopodito. Exopodito desenvolvido, somente com uma cerda lisa na margem externa.

Mandíbula (Fig. 8-IV) - processo incisivo com nove proeminências dentiformes irregulares. Processo molar com cristas irregulares. O palpo mandibular começa a se diferenciar neste estágio, ainda na forma rudimentar.

Maxílula (Fig. 9-IV) - endopodito bissegmentado com uma cerda plumosa no segmento proximal, quatro cerdas plumosas terminais e uma sub-terminal no segmento distal. Endito basal com oito cerdas plumosas. Endito coxal com cinco cerdas plumosas. Protopodito semelhante ao estágio anterior..

Maxila (Fig. 10-IV) - endopodito semelhante ao estágio anterior. Endito basal com cinco cerdas plumosas no lobo proximal e cinco cerdas plumosas no lobo distal. Endito coxal com três cerdas plumosas no lobo proximal e cinco no distal. Exopodito com 21(22) cerdas plumosas marginais.

Primeiro maxilípede (Fig. 11-IV) - basipodito e endopodito semelhantes ao estágio anterior. Exopodito com 10 cerdas plumosas natatórias.

Segundo maxilipede (Fig. 12-IV) - basipodito e endopodito semelhante ao estágio anterior, com o mesmo número de cerdas do estágio anterior. Exopodito com 10 cerdas plumosas natatórias.

\section{ZOEA $\mathrm{V}$}

Carapaça (Fig. 4-V) - apresenta 11(12) cerdas plumosas dorsolaterais. Abdome (Fig. 5-V) com cinco cerdas plumosas no primeiro segmento, os pleópodos dos segmentos 2, 3, 4 e 5 estão mais desenvolvidos. Os urópodos surgem em forma de um pequeno bulbo no sexto segmento. O telso (Fig. $5-\mathrm{V}$ ) semelhante ao estágio anterior. 

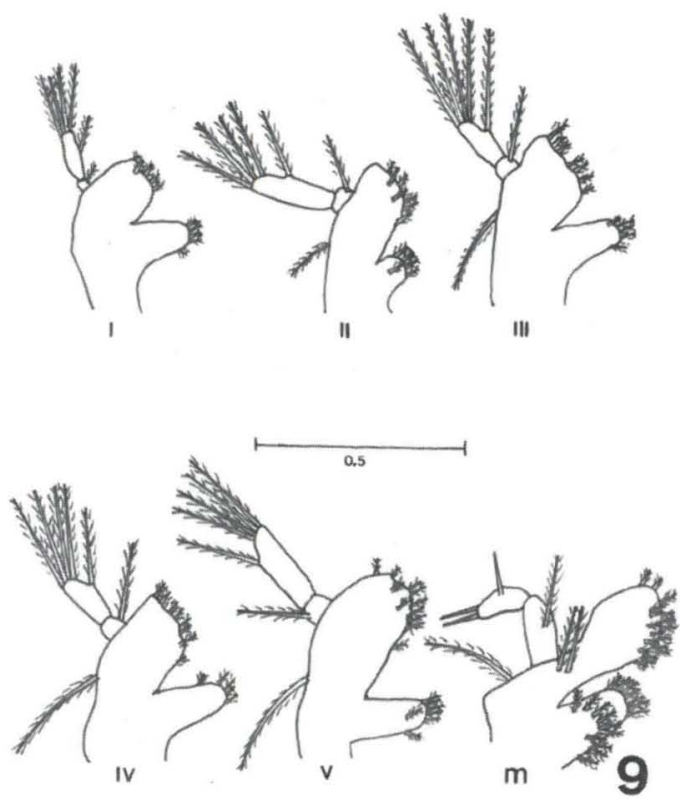

Fig. 9. Cyrtograpsus angulatus, maxilula. (I-V) Estágio de zoea, (m) megalopa. Escala em milímetros.
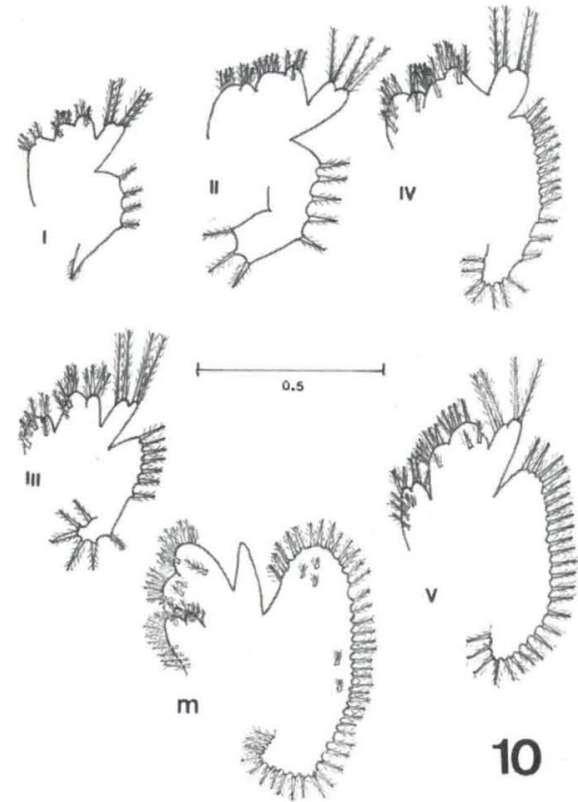

Fig. 10. Cyrtograpsus angulatus, maxila. (I-V) Estágio de zoea, $(\mathrm{m})$ megalopa. Escala em milímetros. 


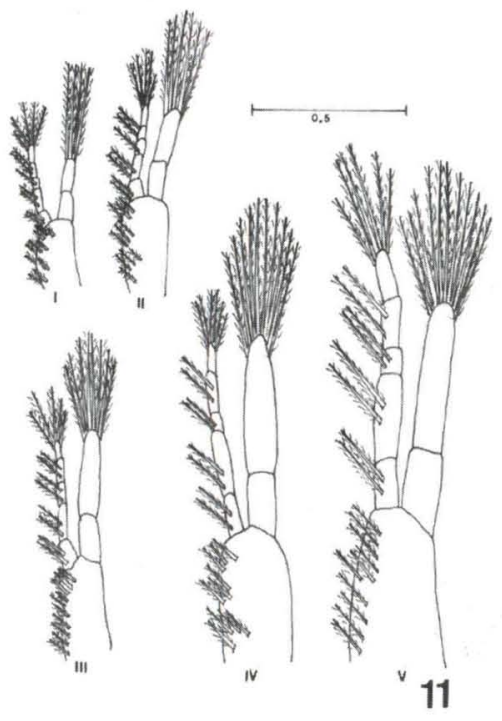

Fig. 11. Cyrtograpsus angulatus, primeiro maxilipede. (I-V) Estágı de zoea. Escala em milimetros.

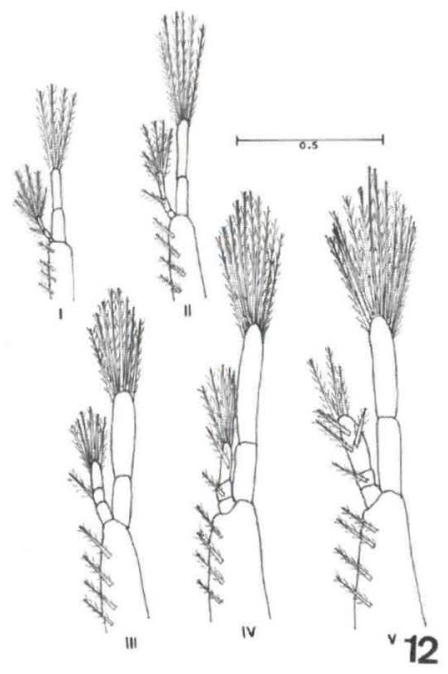

Fig. 12. Cyrtograpsus angulatus, segundo maxilipede. (I-V) Estágio de zoea. Escala em milimetros.

Antênula (Fig. 6-V) - exopodito com 9(8) estetos dispostos em três níveis. Antena (Fig. 7-V) - protopodito com processo espinhoso bastante diferenciado em relação às fileiras de espinhos sendo que os da margem interna apresentam-se maiores do que os da margem externa. Endopodito bem desenvolvido bi-articulado com comprimento equivalente à porção afilada do protopodito. Exopodito bem desenvolvido somente com uma cerda lisa na margem externa. 
Mandíbula (Fig. 8-V) - processo incisivo com 12 proeminências dentiformes irregulares, processo molar com cristas irregulares. Palpo mandibular mais desenvolvido, não segmentado, desprovido de cerdas.

Maxílula (Fig. 9-V) - endopodito bissegmentado com uma cerda plumosa no segmento proximal, quatro cerdas plumosas terminais e uma sub-terminal no segmento distal. Endito basal com 12(14) cerdas plumosas. Endito coxal com oito cerdas plumosas.

Maxila (Fig. 10-V) - endopodito semelhante ao estágio anterior. Endito basal com oito cerdas plumosas no lobo proximal e sete cerdas plumosas no lobo distal. Endito coxal com oito cerdas plumosas no lobo proximal três cerdas plumosas no lobo distal. Exopodito com 26 (25) cerdas plumosas marginais.

Primeiro maxilípede (Fig. 11-V) - basipodito semelhante ao estágio anterior. Endopodito pentassegmentado com 2, 2, 2, 2, 6 cerdas plumosas do segmento proximal para o distal. Exopodito com 12 (11) cerdas plumosas natatórias.

Segundo maxilípede (Fig. 12-V) - basipodito e endopodito semelhantes ao estágio anterior. Exopodito com 12 (11) cerdas plumosas natatórias.

\section{MEGALOPA}

Carapaça (Fig. 4-m) - retangular, com um par de cerdas plumosas nas margens antero-laterais. O rostro é pequeno, defletido para baixo. Abdome (Fig. $5-\mathrm{m}$ ) apresenta-se liso dorsal e lateralmente, com quatro pares de pleópodos e um par de urópodos, dispostos ventralmente, nos segmentos 2 a 6 . O telso (Fig. 5-m) não apresenta cerdas e espinhos nas margens dorsais e laterais.

Antênula (Fig. 6-m) - pedúnculo trissegmentado com três cerdas lisas no segmento proximal, três cerdas lisas no segmento mediano e uma plumosa no segmento distal. Endopodito (flagelo ventral) bissegmentado com três cerdas lisas terminais e uma cerda sub-terminal no articulo distal. Exopodito (flagelo dorsal) tetrassegmentado com o segmento proximal liso, o segundo com cinco estetos, o terceiro com sete estetos e uma cerda plumosa e o quarto com seis estetos e duas cerdas plumosas.

Antena (Fig. 7-m) - pedúnculo trissegmentado, com respectivamente 1, 2, 2 cerdas plumosas do segmento proximal para o distal. Flagelo antenal com sete segmentos com, respectivamente, $0,0,4,1,4,3(2), 3(2)$ cerdas plumosas do segmento proximal para o distal.

Mandíbula (Fig. 8-m) - provida de um lâmina cortante bem quitinizada e lisa. Palpo bissegmentado com oito cerdas plumosas no segmento distal.

Maxílula (Fig. 9-m) - endopodito bissegmentado com uma cerda lisa no segmento proximal e 3(4) cerdas simples no segmento distal. Endito basal com 18 (20) cerdas plumosas e endito coxal com 18 cerdas plumosas.

Maxila (Fig. 10-m) - endopodito liso, não segmentado. Endito basal com 10 cerdas plumosas no lobo proximal e 10 no distal. Endito coxal com 14 cerdas plumosas no lobo proximal e seis cerdas plumosas no lobo distal. Exopodito com 43(45) cerdas plumosas marginais e na superfície cinco cerdas plumosas medianas.

Primeiro maxilípede (Fig. 13-A) - endopodito não segmentado com 2(3) cerdas lisas. Endito basal com 12(10) cerdas plumosas e endito coxal com 10 cerdas 


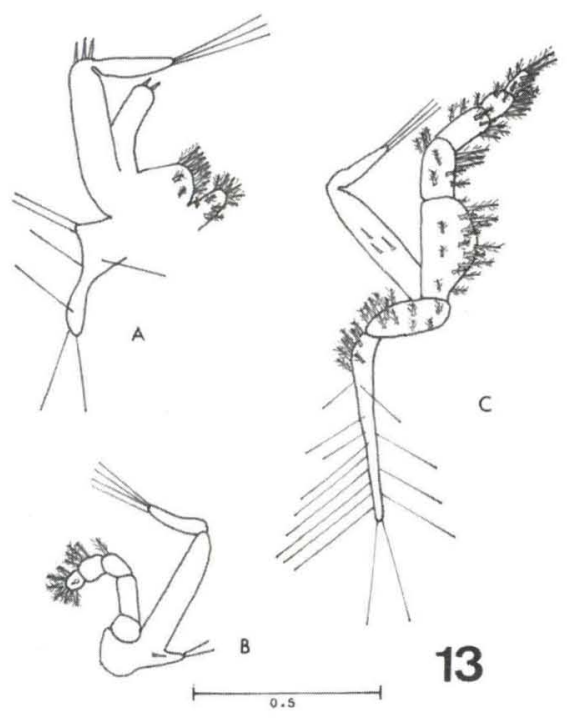

Fig. 13. Cyrtograpsus angulatus, megalopa. (A) Primeiro maxilipede, (B) segundo maxilipede, (C) terceiro maxilipede. Escala em milimetros.

plumosas. Exopodito com 3(2) cerdas lisas na região mediana e três cerdas lisas na região distal. Epipodito com $8(9)$ cerdas lisas.

Segundo maxilipede (Fig. 13-B) - protopodito com uma cerda plumosa. Endopodito pentassegmentado com $0(1), 1,1,4,7(8)$ cerdas plumosas do segmento proximal para o distal. Exopodito bissegmentado com uma cerda plumosa no segmento proximal e quatro cerdas lisas no segmento distal. Epipodito com duas cerdas lisas.

Terceiro maxilípede (Fig. 13-C) - protopodito com 12(14) cerdas plumosas. Endopodito pentassegmentado com 16, 10(8), 8(9), 12, 10 cerdas plumosas do segmento proximal para o distal. Exopodito não segmentado com três cerdas plumosas proximais e três cerdas lisas distais. Epipodito com 8(7) cerdas plumosas e 15 (17) longas cerdas lisas.

Pereiópodos (Fig. 14) - quelípodos $\left(\mathrm{P}_{1}\right)$ simétricos, com os segmentos providos de pequenas cerdas esparsas. $\mathrm{O}$ dedo fixo apresenta três pequenos dentes na margem interna e o dedo móvel 2. Os demais pereiópodos $\left(\mathrm{P}_{2}-\mathrm{P}_{5}\right)$ são bastante semelhantes, morfologicamente, e providos de pequenas cerdas esparsas. O quinto pereiópodo $\left(\mathrm{P}_{5}\right)$ apresenta ainda três longas cerdas, providas de estruturas unciformes distais.

Pleópodos (Fig. 15) - com uma redução em tamanho, do par anterior para o posterior. Seus exopoditos apresentam, respectivamente 16(17), 18(19), 16, 15 cerdas plumosas. Endopodito com três cerdas unciformes distais.

Urópodos (Fig. 15-U) - Desprovido de endopodito. Exopodito bissegmentado com $8(10)$ cerdas plumosas no segmento distal e uma no proximal. 


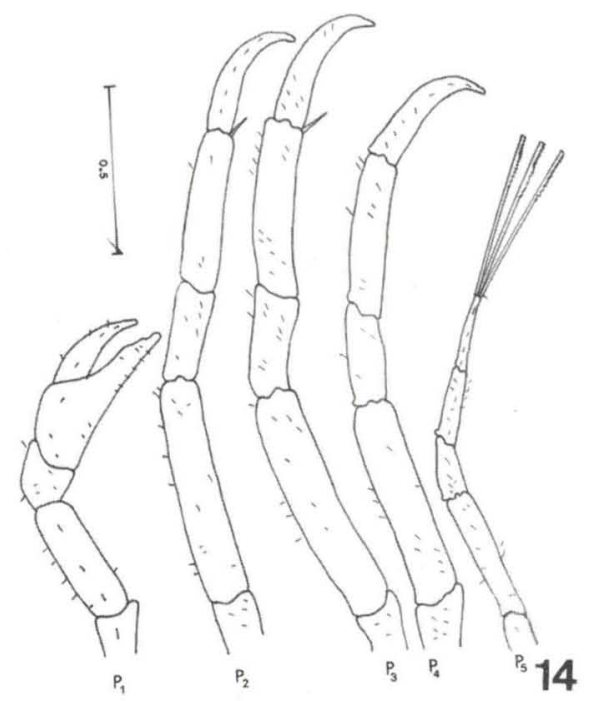

Fig. 14. Cyrtograpsus angulatus, megalopa. $\left(\mathrm{P}_{1}-\mathrm{P}_{5}\right)$ Pereiópodos. Escala em milimetros.

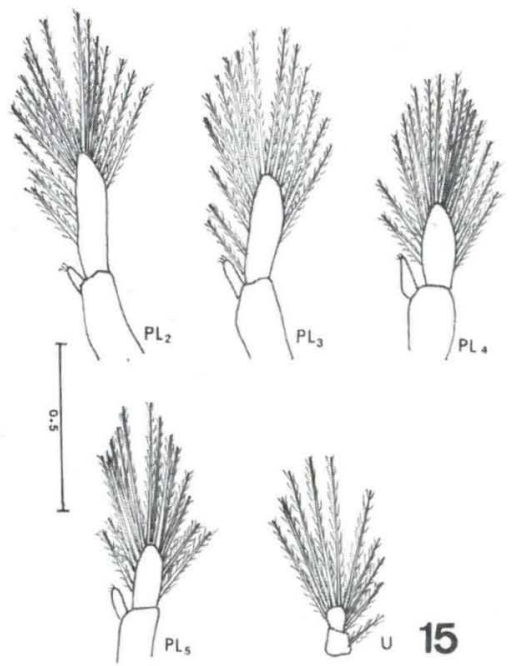

Fig. 15. Cyrtograpsus angulatus, megalopa. $\left(\mathrm{PL}_{2}-\mathrm{PL}_{5}\right)$ Pleópodos, $(\mathrm{U})$ urópodo. Escala em milimetros.

\section{DISCUSSÃO E CONCLUSÃO}

Entre os Brachyura com desenvolvimento pós-embrionário conhecido, a fase de zoea pode ser ausente ou constituída por um número variável de estágios (entre um e oito), de acordo com o grupo ou espécie considerada. Em certos grupos, como por exemplo nos Majidae, o número de estágios de zoea são sempre dois, cuja constância tem sido utilizada como um dos caracteres para definição da família. Por 
outro lado, existem grupos onde cada gênero ou espécie apresenta um determinado número de estágios e outros onde ocorrem variações individuais, dentro da mesma espécie (RIEGER \& HEBLING 1993).

Na família Grapsidae, de acordo com a bibliografia e os resultados do presente trabalho, foram criadas 28 espécies até o término do desenvolvimento larval.

Das espécies de Plagusinae apenas uma teve seu desenvolvimento larval concluído, apresentando seis estágios na fase de zoea. De Grapsinae, apenas duas tiveram seu desenvolvimento larval completo, sendo uma com cinco estágios na fase de zoea e outra com cinco ou seis estágios na fase de zoea. Sesarminae, dezessete espécies tiveram seus desenvolvimentos larvais concluídos, sendo uma com dois estágios na fase de zoea, duas com três estágios na fase de zoea, oito com quatro estágio na fase de zoea, uma com cinco ou seis estágios na fase de zoea e cinco com cinco estágios na fase de zoea. De Varuninae, oito espécies tiveram seus desenvolvimentos larvais completos, sendo sete com cinco estágios na fase de zoea e uma com cinco ou seis estágios na fase de zoea (SCELZO \& BASTIDA 1978; WILSON 1980; Fransozo \& Hebling 1986). Plagusiinae, Grapsinae e Varuninae apresentam cinco ou sies estágios na fase de zoea.

O significado biológico de um maior ou menor número de estágios larvais, encontrados no desenvolvimento larval dos crustáceos, tem merecido diversas interpretações. De acordo com WATERMAN \& CHACE (1960), um importante fenômeno, que tem ocorrido independentemente em muitos grupos de crustácea, é a tendência de estender o período embrionário e encurtar ou eliminar, correspondentemente, as fases larvais. Dentre as sub-famílias, Sesarminae é a que apresenta uma maior variação no número de estágios na fase de zoea, sendo a maioria com quatro estágios.

Dentre as espécies encontradas de Varuninae, a grande maioria apresenta cinco estágios na fase de zoea e dentre as espécies do gênero Cyrtograpsus Dana, 1851, com desenvolvimento larval estudado, todas apresentam cinco estágios na fase de zoea, embora no desenvolvimento larval de Cyrtograpsus altimanus as larvas não tenham sido individualizadas.

Cyrtograpsus angulatus, apresenta cinco estágios na fase de zoea, cujas invariabilidades foram confirmadas em três experimentos, com larvas oriundas de três fêmeas ovígeras diferentes. Todavia, é importante ressaltar, que nos três experimentos, as larvas forma mantidas isoladas, com acompanhamento individual, fato que possibilitou a constatação das ecdises e estágios sucessivos, em cada uma das zoeas estudadas.

De acordo com Hebling \& Negreiros-Fransozo (1983), esta maior rapidez na metamorfose pode ser considerada como uma possível linha de especialização, por envolver um menor período de vida plantônica. FRANSOZO \& HEBLING (1982), ao analisarem a duração e o número de estágios larvais entre os Majidae, concluíram que uma maior brevidade no tempo requerido pela metamorfose pode representar um maior grau de especialização, cujo fato pode ser interpretado como responsável pelo grande número de espécies que ocorrem nesta família. O mesmo fato foi confirmado por HEBling \& Fransozo (1982) e HEBLING \& NEGREIROS- 
Fransozo (1983) para as espécies do gênero Paguristes Dana, 1852, representado por mais de uma centena de espécies. Neste caso, a pequena representatividade numérica do gênero Cyrtograpsus estaria correlacionada com a maior duração da metamorfose, o qual tanto em C. angulatus como em C. altimanus, ultrapassa 30 dias.

SANDifer \& SMith (1979), em estudos com Paleomonidae, afirmaram que, além de ser influenciada por fatores ambientais, a tendência de uma determinada larva passar por um certo número de estágios pode ser hereditária. Além disso, sugeriram que as variações numéricas e de duração dos estágios larvais plantônicos podem auxiliar na dispersão da espécie e aumentar a sobrevivência dos genótipos parentais. Neste aspecto, a grande distribuição geográfica de $C$. angulatus poderia ser explicada pela sua fase de zoea relativamente prolongada, quando comparada com a de outros Brachyura.

A busca de caracteres diagnósticos, isentos das influências de convergências ou radiações adaptativas e passíveis de serem utilizadas nos estudos sistemáticos, tem sido a maior preocupação dos modernos taxonomistas. GUINOT (1978), ao apresentar uma nova classificação evolutiva dos Brachyura, salienta o valor taxônomico da anatomia dos órgãos sexuais em função de sua pequena dependência às pressões transformadoras exercida pelo meio.

De acordo com RicE (1980), a família Grapsidae é representada por cerca de 300 espécies, cuja maioria vive em águas rasas, marinhas ou estuarinas. Várias espécies são oceânicas, outras ocorrem em nichos especializados e algumas conquistaram a água doce ou são semi-terrestres.

Considerando-se todas estas possibilidade de vida, em diferentes ambientes, torna-se evidente que as espécies atuais de Grapsidae devem ter sofrido várias convergências adaptativas que, obviamente, acarretaram inúmeros enganos nas classificações baseadas exclusivamente nos caracteres dos adultos.

RICE (1980), ao justificar a utilização da morfologia das zoeas na classificação dos Brachyura afirma que, ao contrário dos adultos, as formas larvais destes animais estão adaptadas para viver em um meio aquático relativamente homogêneo e provavelmente livres das situações de convergência adaptativas às quais os adultos estão sujeitos.

$\mathrm{Na}$ busca de caracteres externos facilmente visíveis para identificação dos diferentes estágios de Cyrtograpsus angulatus e Cyrtograpsus altimanus podemos exemplificar algumas estruturas. No que se refere a antênula: os números de estetos ou cerdas apresentam-se numericamente distintos em cada um dos estágios; antena: Cyrtograpsus altimanus apresenta o protopodito, do primeiro e segundo estágio da fase de zoea, com processo espinhoso em quase todo seu comprimento, o qual não coincide com a região do exopodito que apresenta as duas cerdas laterais lisas. Cyrtograpsus angulatus apresenta o protopodito, do primeiro e segundo estágio da fase de zoea, com processo espinhoso à partir da sua metade distal o qual coincide com a região do exopodito que apresenta as duas cerdas laterais lisas. Já a partir do terceiro estágio da fase de zoea passamos a encontrar o processo espinhoso em praticamente todo o comprimento do protopodito, bem como a presença de um bulbo do endopodito. A partir do quarto estágio da fase de zoea o exopodito antenal 
apresenta-se somente com um espinho lateral externo; primeiro maxilípede: Cyrtograpsus altimanus apresenta o exopodito não segmentado, endopodito apresenta no terceiro articulo finas cerdas ou plumulas em uma de suas bordas. Cyrtograpsus angulatus apresenta o exopodito do primeiro maxilípede bissegmentado; segundo maxilípede: o número de cerdas do endopodito apresenta-se diferente para as duas espécies.

Por outro lado, a análise dos caracteres das zoeas de Cyrtograpsus angulatus e Cyrtograpsus altimanus demonstra uma grande semelhança morfológica, cujas identificações específicas só podem ser obtidas com o auxílio de várias estruturas, avaliadas em conjunto, em cada um dos estágios larvais, os quais são apresentados nas tabelas III, IV, V, VI e VII.

Tabela III. Diferenças entre os principais caracteres morfológicos das zoea I de Cyrtograpsus angulatus e $C$. altimanus.

\begin{tabular}{|c|c|c|}
\hline Caracteres & Cyrtograpsus angulatus & Cyrtograpsus altimanus \\
\hline Antênula: Estetos (E) Cerdas (C) & $3 E+1 C$ & $2(E)+2(C)$ \\
\hline $\begin{array}{l}\text { Maxilula: número de cerdas plumosas }(\mathrm{pl}) \text { e } \\
\text { lisas (I) no endopodito }(\mathrm{E}) \text {, endito basal } \\
(\mathrm{EB}) \text {, endito coxal }(\mathrm{EC}) \text {, protopodito }(\mathrm{P})\end{array}$ & $1 p l+5 p l(E) ; 5 p l(E B) ; 5 p l(E C) ; O(P)$ & $1 p l+5 p l(E) ; 5 p l(E B) ; 5 p l(E C) ; 1 p l(P)$ \\
\hline $\begin{array}{l}\text { Maxila: número de cerdas plumosas ( } p l) \text { e } \\
\text { lisas (I) no exopodito (Ex); endopodito (E); } \\
\text { endito basal (EB); endito coxal (EC) }\end{array}$ & $\begin{array}{l}4 p l(E X) ; 2 p l+2 p l(E) ; 4(5) p l+3(4) p l(E B) \\
3 p l+2 p l(E C)\end{array}$ & $\begin{array}{l}4 p l(E x) ; 2 p l+2 p l(E) ; 5 p l+4 p l(E B) \\
3 p l+3 p l(E C)\end{array}$ \\
\hline $\begin{array}{l}\text { Primeiro maxillpede: número de cerdas no } \\
\text { basipodito }(B) \text {, exopodito }(E x) \text {, endopodito }\end{array}$ & $\begin{array}{l}\text { 10pl(B); 0+4pl(Ex); } \\
2 p l, 2 p l, 1 p l, 2 p l, 5 p l(E)\end{array}$ & $\begin{array}{l}\text { 10pl(B);; } 4 \mathrm{pl}(\mathrm{Ex}) \\
2 \mathrm{pl}, 2 \mathrm{pl}, 1 \mathrm{pl}, 2 \mathrm{pl}, 5 \mathrm{pl}(\mathrm{E})\end{array}$ \\
\hline $\begin{array}{l}\text { Segundo maxilipede número de cerdas no } \\
\text { basipodito }(B) \text {, exopodito }(E x) \text {, endopodito }\end{array}$ & $4 p|(B) ; 0+4 p|(E x) ; 0,1 p l, 6 p l(E)$ & $4 \mathrm{pl}(\mathrm{B}) ; 0+4 \mathrm{pl}(\mathrm{Ex}) ; 1 \mathrm{pl}, 1 \mathrm{pl}, 6 \mathrm{pl}(\mathrm{E})$ \\
\hline
\end{tabular}

Tabela IV. Diferenças entre os principais caracteres morfológicos das zoea II de Cyrtograpsus angulatus e Cyrtograpsus altimanus.

\begin{tabular}{|c|c|c|}
\hline Caracteres & Cyrtograpsus angulatus & Cyrtograpsus altimanus \\
\hline Antênula: Estetos (E) Cerdas (C) & $4 E+1 C$ & $4(E)+2(C)$ \\
\hline $\begin{array}{l}\text { Maxilula: número de cerdas plumosas }(\mathrm{pl}) \text { e } \\
\text { lisas (I) no endopodito }(\mathrm{E}) \text {, endito basal } \\
(\mathrm{EB}) \text {, endito coxal (EC), protopodito (P) }\end{array}$ & $1 p l+5 p l(E) ; 7 p l(E B) ; 5 p l(E C) ; 1 p l(P)$ & $1 p|+5 p|(E) ; 7 p l(E B) ; 5 p l(E C) ; 1 p l(P)$ \\
\hline $\begin{array}{l}\text { Maxila: número de cerdas plumosas (pl) e } \\
\text { lisas (I) no exopodito (Ex); endopodito (E); } \\
\text { endito basal (EB); endito coxal (EC) }\end{array}$ & $\begin{array}{l}8 p l(E x) ; 2 p l+2 p l(E) ; 5 p l+4 p l(E B) \\
3 p l+3 p l(E C)\end{array}$ & $\begin{array}{l}8 p l(E x) ; 2 p l+2 p l(E) ; 5 p l+4 p l(E B) \\
4 p l+3 p l(E C)\end{array}$ \\
\hline $\begin{array}{l}\text { Primeiro maxilipede: número de cerdas no } \\
\text { basipodito }(B) \text {, exopodito }(E x) \text {, endopodito }\end{array}$ & $\begin{array}{l}\text { 10pl(B); 0+6pl(Ex); } \\
2 p l, 2 p l, 1 p l, 2 p l, 5 p l(E)\end{array}$ & $\begin{array}{l}\text { 10pl(B); 6pl(Ex); } \\
\text { 2pl, 2pl, 1pl, 2pl, 5pl(E) }\end{array}$ \\
\hline $\begin{array}{l}\text { Segundo maxilipede número de cerdas no } \\
\text { basipodito (B), exopodito (Ex), endopodito }\end{array}$ & $4 \mathrm{pl}(\mathrm{B}) ; 0+6 \mathrm{pl}(\mathrm{Ex}) ; 0,1 \mathrm{pl}, 6 \mathrm{pl}(\mathrm{E})$ & $4 p l(B) ; 0+6 p l(E x) ; 1 p l, 1 p l, 6 p l(E)$ \\
\hline
\end{tabular}

Os estudos comparativos das megalopas de Cyrtograpsus angulatus e Cyrtograpsus altimanus evidenciam uma grande semelhança na morfologia geral mas existem alguns caracteres que as diferenciam e que permitem as suas identificações específicas, cujos mais importantes são apresentados na tabela VIII.

As megalopas de Cyrtograpsus apresentam importantes diferenças, pelo que foi possível avaliar no trabalho de SCELZO \& BASTIDA (1978), podemos destacar: 1) $\mathrm{O}$ endopodito da antênula em $C$. altimanus é unissegmentado enquanto que $C$. 
angulatus é bissegmentado; 2) O endopodito da maxílula em C. altimanus é unissegmentado e bissegmentado em $C$. angulatus; 3 ) O terceiro artículo do endopodito do primeiro maxilípede de C. altimanus apresenta finas cerdas ou pelos em suas bordas, o mesmo não acontecendo com $C$. angulatus.

Tabela V. Diferenças entre os principais caracteres morfológicos das zoea III de Cyrtograpsus angulatus e Cyrtograpsus altimanus.

\begin{tabular}{|c|c|c|}
\hline Caracteres & Cyrtograpsus angulatus & Cyrtograpsus altimanus \\
\hline Antènula: Estetos $(\mathrm{E})$ Cerdas $(\mathrm{C})$ & $4(5) E+1 C$ & $3(E)+3(C)$ \\
\hline $\begin{array}{l}\text { Maxilula: número de cerdas plumosas ( } \mathrm{pl} \text { ) e } \\
\text { lisas (I) no endopodito }(\mathrm{E}) \text {, endito basal } \\
\text { (EB), endito coxal }(E C) \text {, protopodito }(P)\end{array}$ & $1 p|+5 p|(E) ; 7 p|(E B) ; 5 p|(E C) ; 1 p \mid(P)$ & $1 \mathrm{pl}+5 \mathrm{pl}(\mathrm{E}) ; 7 \mathrm{pl}(\mathrm{EB}) ; 5 \mathrm{pl}(\mathrm{EC}) ; 1 \mathrm{pl}(\mathrm{P})$ \\
\hline $\begin{array}{l}\text { Maxila: número de cerdas plumosas ( } \mathrm{pl} \text { ) e } \\
\text { lisas (I) no exopodito (Ex); endopodito (E); } \\
\text { endito basal (EB); endito coxal (EC) }\end{array}$ & $\begin{array}{l}\text { 13pl(Ex); } 2 \mathrm{pl}+2 \mathrm{pl}(\mathrm{E}) ; 4(5) \mathrm{pl}+4 \mathrm{pl}(\mathrm{EB}) \\
3(4) \mathrm{p} \mid+3 \mathrm{pl}(\mathrm{EC})\end{array}$ & $\begin{array}{l}\text { 13pl(Ex); } 2 p l+2 p l(E) ; 4(5) p \mid+4 p l(E B) ; \\
3(4) p l+3 p l(E C)\end{array}$ \\
\hline $\begin{array}{l}\text { Primeiro maxilipede: número de cerdas no } \\
\text { basipodito }(B) \text {, exopodito (Ex), endopodito }\end{array}$ & $\begin{array}{l}\text { 10pl(B); } 0+8 p l(E x) \\
2 p l, 2 p l, 2 p l, 2 p l, 2 p l(E)\end{array}$ & $\begin{array}{l}\text { 10pl(B); 8pl(Ex); } \\
\text { 2pl2pl, 3pl, 2pl, 5pl(E) }\end{array}$ \\
\hline $\begin{array}{l}\text { Segundo maxilipede número de cerdas no } \\
\text { basipodito }(B) \text {, exopodito }(E x) \text {, endopodito }\end{array}$ & $4 p l(B) ; 0+8 p l(E x) ; 0,1 p l, 6 p l(E)$ & $4 p \mid(B) ; 0+8 p l(E x) ; 1 p l, 1 p l, 6 p l(E)$ \\
\hline
\end{tabular}

Tabela VI. Diferenças entre os principais caracteres morfológicos das zoea IV de Cyrtograpsus angulatus e Cyrtograpsus altimanus.

\begin{tabular}{|c|c|c|}
\hline Caracteres & Cyrtograpsus angulatus & Cyrtograpsus altimanus \\
\hline Antênula: Estetos (E) Cerdas (C) & $5 E+1 C$ & $3(E)+1(C)$ \\
\hline $\begin{array}{l}\text { Maxilula: número de cerdas plumosas ( } \mathrm{pl} \text { ) e } \\
\text { lisas (I) no endopodito (E), endito basal } \\
\text { (EB), endito coxal (EC), protopodito (P) }\end{array}$ & $\begin{array}{l}1 p l+5 p l(E) ; 8 p l(E B) ; 5 p l(E B) ; 5 p l(E C) \\
1 p l(P)\end{array}$ & $\begin{array}{l}1 \mathrm{pl}+5 \mathrm{pl}(\mathrm{E}) ; 11+10 \mathrm{pl}(\mathrm{EB}) ; 6 \mathrm{pl}(\mathrm{EC}) \\
1 \mathrm{pl}(\mathrm{P})\end{array}$ \\
\hline $\begin{array}{l}\text { Maxila: nủmero de cerdas plumosas (pl) e } \\
\text { lisas (I) no exopodito (Ex); endopodito (E); } \\
\text { endito basal (EB); endito coxal (EC) }\end{array}$ & $\begin{array}{l}21(22) p l(E x) ; 2 p l+2 p l(E) ; 5 p l+5 p l(E B) \\
5 p l+3 p l(E C)\end{array}$ & $\begin{array}{l}19 p l(E x) ; 2 p l+2 p l(E) ; 6 p l+5 p l(E B) \\
5 p l+5 p l(E C)\end{array}$ \\
\hline $\begin{array}{l}\text { Primeiro maxilipede: número de cerdas no } \\
\text { basipodito }(B) \text {, exopodito }(E x) \text {, endopodito }\end{array}$ & $\begin{array}{l}\text { 10pl(B); 0+10pl(Ex); } \\
2 \mathrm{pl}, 2 \mathrm{pl}, 2 \mathrm{pl}, 2 \mathrm{pl}, 6 \mathrm{pl}(\mathrm{E})\end{array}$ & $\begin{array}{l}\text { 10pl(B); 10pl(Ex); } \\
2 \mathrm{pl}, 2 \mathrm{pl}, 3 \mathrm{pl}, 2 \mathrm{pl}, 5 \mathrm{pl}(\mathrm{E})\end{array}$ \\
\hline $\begin{array}{l}\text { Segundo maxilipede número de cerdas no } \\
\text { basipodito }(B) \text {, exopodito }(E x) \text {, endopodito }\end{array}$ & $4 p|(B) ; 0+10 p l(E x) ; 0,1 p l, 6 p|(E)$ & $4 p \mid(B) ; 0+10 p l(E x) ; 1 p l, 1 p l, 6 p l(E)$ \\
\hline
\end{tabular}

Tabela VII. Diferença entre os principais caracteres morfológicos das zoea V de Cyrtograpsus angulatus e Cyrtograpsus altimanus.

\begin{tabular}{|c|c|c|}
\hline Caracteres & Cyrtograpsus angulatus & Cyrtograpsus altimanus \\
\hline Antênula: Estetos (E) Cerdas (C) & $9(8) E$ & $9(E)+1(C)$ \\
\hline $\begin{array}{l}\text { Maxilula: número de cerdas plumosas }(\mathrm{pl}) \text { e } \\
\text { lisas (I) no endopodito }(\mathrm{E}) \text {, endito basal } \\
(E B) \text {, endito coxal }(E C) \text {, protopodito }(P)\end{array}$ & $\begin{array}{l}1 p l+5 p l(E) ; 12(14) p l(E B) ; 8 p l(E C) \\
1 p l(P)\end{array}$ & $\begin{array}{l}1 p l+5 p l(E) ; 2 \mid+12 p l(E B) ; 9 p l(E C) \\
1 p l(P)\end{array}$ \\
\hline $\begin{array}{l}\text { Maxila: número de cerdas plumosas (pl) e } \\
\text { lisas (I) no exopodito }(E x) \text {; endopodito }(E) \text {; } \\
\text { endito basal (EB); endito coxal (EC) }\end{array}$ & $\begin{array}{l}26(25) p l(E x) ; 2 p l+2 p l(E) ; 6 p l+8 p l(E B) ; \\
5 p l+5 p l(E C)\end{array}$ & $\begin{array}{l}27 p l(E x) ; 2 p l+2 p l(E) ; 6 p l+8 p l(E B) \\
5 p l+5 p l(E C)\end{array}$ \\
\hline $\begin{array}{l}\text { Primeiro maxilipede: número de cerdas no } \\
\text { basipodito }(B) \text {, exopodito }(E x) \text {, endopodito }\end{array}$ & $\begin{array}{l}\text { 10pl(B); } 0+12(11) p l(E x)_{i} \\
2 p l, 2 p l, 2 p l, 2 p l, 6 p l(E)\end{array}$ & $\begin{array}{l}\text { 10pl(B); 12pl(Ex); } \\
2 \mathrm{pl}, 2 \mathrm{pl}, 3 \mathrm{pl}, 2 \mathrm{pl}, 5 \mathrm{pl}(\mathrm{E})\end{array}$ \\
\hline $\begin{array}{l}\text { Segundo maxillpede número de cerdas no } \\
\text { basipodito (B), exopodito (Ex), endopodito }\end{array}$ & $4 p l(B) ; 0+12(11) p l(E x) ; 0,1 p l, 6 p l(E)$ & $4 p|(B) ; 0+12 p l(E x) ; 1 p l, 1 p l, 6 p|(E)$ \\
\hline
\end{tabular}


Tabela VIII. Diferença entre os principais caracteres morfológicos das megalopas de Cyrtograpsus angulatus e Cyrtograpsus altimanus.

\begin{tabular}{|c|c|c|}
\hline Caracteres & Cyrtograpsus angulatus & Cyrtograpsus altimanus \\
\hline Antênula: número de segmentos do endopodito & & 1 \\
\hline $\begin{array}{l}\text { Antênula: número de cerdas (C) plumosas ( } \mathrm{pl}) \\
\text { e lisa (I), estetos (E) do exopodito (Ex) e do } \\
\text { endopodito (ED) }\end{array}$ & $\begin{array}{l}0,5 \mathrm{E}, 7 \mathrm{E}+1 \mathrm{Cpl}, 6 \mathrm{E}+2 \mathrm{Cpl}(\mathrm{Ex}) \\
\quad 0,4 \mathrm{Cl}(\mathrm{ED})\end{array}$ & $0,7 \mathrm{E}, 6 \mathrm{E}, 4 \mathrm{E}+1 \mathrm{Cl}+1 \mathrm{Cpl}(\mathrm{Ex}) ; 4 \mathrm{Cl}(\mathrm{ED})$ \\
\hline Maxilula: número de segmentos do endopodito & 2 & 1 \\
\hline $\begin{array}{l}\text { Maxilula: número de cerdas plumosas (pl) e } \\
\text { lisas (l), estetos }(E) \text {, no endopodito }(E D) \text {, } \\
\text { endito basal }(E B) \text {, endito coxal }(E C) \text {. } \\
\text { protopodito }(P)\end{array}$ & $\begin{array}{l}1 \mathrm{Cl}+3(4) \mathrm{Cl}(\mathrm{ED}) ; 18(20) \mathrm{Cpl}(\mathrm{EB}) \\
18 \mathrm{pl}(\mathrm{EC}) ; 1 \mathrm{Cpl}(\mathrm{P})\end{array}$ & $\begin{array}{l}5 \mathrm{Cl}+1 \mathrm{Cpl}(\mathrm{ED}) ; 26 \mathrm{Cpl}(\mathrm{EB}) \\
14 \mathrm{Cpl}(\mathrm{EC}) ; 3 \mathrm{Cl}(\mathrm{P})\end{array}$ \\
\hline $\begin{array}{l}\text { Maxila: número de cerdas plumosas (pl) e lisas } \\
\text { (I) no exopodito (Ex); endopodito (ED); endito } \\
\text { basal (EB); endito coxal (EC) }\end{array}$ & $\begin{array}{l}48(50) \mathrm{Cpl}(\mathrm{Ex}) ; 0(\mathrm{ED}) ; 20 \mathrm{Cpl}(\mathrm{EB}) \\
20 \mathrm{Cpl}(\mathrm{EC})\end{array}$ & $\begin{array}{l}50 \mathrm{Cpl}(\mathrm{Ex}) ; 1 \mathrm{Cpl}+1 \mathrm{Cl}(\mathrm{ED}) \\
20 \mathrm{Cpl}(\mathrm{EB}) ; 20 \mathrm{Cpl}(\mathrm{EC})\end{array}$ \\
\hline $\begin{array}{l}\text { Primeiro maxilipede: número de cerdas (C) } \\
\text { plumosa (pl) e lisas (I) no exopodito (Ex), } \\
\text { endopodito (ED), endito basal (EB), endito } \\
\text { coxal (EC), epipodito (ep) }\end{array}$ & $\begin{array}{l}6(5) \mathrm{Cl}(\mathrm{Ex}) ; 2(3) \mathrm{Cl}(\mathrm{ED}) \\
\text { 12(10)Cpl(EB); 10Cpl(EC); } \\
\text { 8(9)Cl(Ep) }\end{array}$ & $\begin{array}{l}5 \mathrm{Cpl}(\mathrm{Ex}) ; 3 \mathrm{Cl}(\mathrm{ED}) ; 11 \mathrm{Cpl}(\mathrm{EB}) \\
\quad 13 \mathrm{pl}(\mathrm{EC}) ; 8 \mathrm{Cl}(\mathrm{Ep})\end{array}$ \\
\hline $\begin{array}{l}\text { Segundo maxilipede: nủmero de segmentos do } \\
\text { endopodito }\end{array}$ & & 4 \\
\hline $\begin{array}{l}\text { Segundo maxilipede: número de cerdas (C) no } \\
\text { exopodito (Ex), Endopodito (ED), protopodito } \\
\text { (Ep) }\end{array}$ & $\begin{array}{l}\text { 1Cpl+4Cl(EX); } 0(1), 1,1,4 \\
\quad 7(8) \mathrm{Cpl}(\mathrm{ED}) ; 1 \mathrm{Cpl}(\mathrm{P}) ; 2 \mathrm{Cl}(\mathrm{Ep})\end{array}$ & $\begin{array}{l}5 \mathrm{Cpl}(\mathrm{Ex}) ; 1,1,5,8 \mathrm{Cpl}(\mathrm{ED}) ; 1 \mathrm{Cpl}(\mathrm{P}) ; \\
2 \mathrm{Cl}(\mathrm{Ep})\end{array}$ \\
\hline
\end{tabular}

\section{REFERÊNCIAS BIBLIOGRÁFICAS}

Boschi, E.E.; M.A. Scelzo \& B. Goldstein. 1967. Desarollo larval de dos especies de crustaceos decapodos en el laboratório, Pachycheles haigae Rodrigues da Costa (Porcellanidae) y Chasmagnathus granulata (Grapsidae). Boln. Inst. Biol. Mar. 12: 1-44.

CoElHo, P.A. 1971. A distribuição dos crustáceos decápodos reptantes do norte do Brasil. Trab. Ocean. Univ. Fed. Pernambuco, Recife, 9/11: 223-238.

COELHO, P.A. \& M.A. RAMOS. 1972. A constituição e a distribuição da fauna de decápodos no litoral leste da América do Sul, entre as latitudes de $5^{\circ} \mathrm{N}$ e $39^{\circ} \mathrm{S}$. Trab. Ocean. Univ. Fed. Pernambuco, Recife, 13: 133-236.

CoelHo, P.A.; M.R. Porto \& M.L. Koening. 1980. Biogeografia e bionomia dos crustáceos do litoral equatorial brasileiro. Trab. Ocean. Univ. Fed. Pernambuco, Recife, 15: 7-138.

Diaz, H. \& J.J. EwaLD. 1968. A comparison between the larval development of Metasesarma rubripes (Rathbun) and Sesarma ricordi (H. Milne Edwards) (Brachyura, Grapsidae) under laboratory conditions. Crustaceana 2 (Supl. 2): 225-248.

Fausto-FilHo, J. 1966. Primeira contribuição ao inventário dos Crustáceos Decápodos marinhos do nordeste brasileiro. Arq. Est. Biol. Mar. Univ. Fed. Ceará 6 (1): 31-37.

- 1967. Segunda contribuição ao inventário dos Crustáceos Decápodos marinhos do nordeste brasileiro. Arq. Est. Biol. Mar. Univ. Fed. Ceará 7 (1): 11-14.

1968. Terceira contribuição ao inventário dos Crustáceos Decápodos 
marinhos do nordeste brasileiro. Arq. Est. Biol. Mar. Univ. Fed. Ceará 8 (1): 43-45.

Fransozo A. \& N.J. Hebling. 1982. Desenvolvimento pós-embrionário de Mithrax hispidus Herbst, 1970 (Decapoda, Majidae), em laboratório. Ciência e Cultura 34 (3): 385-395.

Fransozo, A. \& N.J. Hebling. 1986. Desenvolvimento larval de Sesarma (Holometopus) rectum Randall, 1840 (Decapoda, Grapsidae), em laboratório. Rev. Brasil. Biol. 46 (2): 353-364.

GuINOT, D. 1978. Principes d'une classification évolutive des Crustacés Décapodes Brachyoures. Bull. Biol. Fr. Belg. 112 (3): 211-292.

Hebling, N.J. \& A. Fransozo. 1982. Desenvolvimento pós embrionário de Paguristes erytrops Holthuis, 1959 (Decapoda, Diogenidae), em laboratório. Rev. Brasil. Biol. 42 (1): 117-2128.

HEBling, N.J. \& M.L. NEgREIROS-FrANSOZO. 1983. Desenvolvimento pós-embrionário de Paguristes tortugae Schmitt, 1933 (Decapoda, Diogenidae), em laboratório. Bol. Zool. Univ., São Paulo, 6: 157-176.

Holthuis, L.B. 1959. The Crustacea Decapoda of Suriname (Dutch Guiana). Zool. Verh. Rijksmus. Nat. Hist., Leiden, 44: 1-296.

MELo, G.A.S. 1996. Taxonomia e padrões distribucionais e ecológicos dos Brachyura (Crustacea; Decapoda) do litoral sudeste do Brasil. Tese de Doutorado, não publicada, Universidade de São Paulo, Museu de Zoologia, São Paulo, 215p.

Negreiros-Fransozo, M. L.; A. Fransozo \& N.J. Hebling. 1989. Larval development of Persephona mediterranea Herbst, 1794 (Brachyura, Leucosidae) under laboratory conditions. Crustaceana 57 (2): 177-193.

Rathbun, M.J. 1918. The grapsoid crabs of América. Bull. U.S. Nat. Mus. 97: $1-461$.

RicE, A.L. 1980. Crab zoeal morphology and its bearing on the classification of the Brachyura. Trans. Zool. Soc. Lond. 35: 271-424.

RIEGER, P.J. 1996. Desenvolvimento larval de Uca (Celuca) uruguayensis Nobili, 1901, Uca (Minuca) burgersi Holthuis, 1967, Uca (Minuca) mordax Smith, 1870 e Uca (Minuca) vocator Herbst, 1804 (Crustacea, Decapoda, Ocypodidade), em laboratório. Tese de Doutorado, não publicada, Instituto de Biociências, Universidade Estadual Paulista, Rio Claro, 133p.

RIEGER, P.J. \& N.J. HeBling. 1993. Desenvolvimento larval de Hepatus pudibundus (Herbst, 1785) (Decapoda, Calappidae), em laboratório. Rev. Brasil. Biol. 53 (4): 513-528.

Rodrigues, M.D. \& N.J. HeBling. 1989. Ucides cordatus Linnaeus, 1763 (Crustacea, Decapoda). Complete larval development under laboratory conditions and its systematic position. Revta bras. Zool. 6 (1): 147-166.

SANDIFER, P.A. \& T.I.J. SMITH. 1979. Possible significance of variation in the larval development of Paleomonid shrimp. Jour. Exp. Mar. Biol. Ecol. 39: 55-64.

ScElzo M.A. \& V.L. BASTIDA. 1978. The larval development and metamorphosis os the crab Cyrtograpsus altimanus (Brachyura, Grapsidae) in the laboratory with observations on the ecology of the species. Physis. Secc. A. Oceanos Org. 
38 (94): 103-126.

Waterman, T.H. \& F.A. Chace JR. 1960. General Crustacean Biology, p.1-33. In: T.H. WATERMAN (Ed). The physiology of Crustacea. Metabolism and Growth. New York, Academic Press.

Williams A.B. 1984. Shrimps, lobsters and crabs of the Atlantic coast the eastern United States, maine to Florida. Washington, Smithsonian Intitute Press, XVIII+55p.

WiLson, K. 1980. Studies on Decapod Crustacea from the Indian river region of Florida. XV. The larval development under laboratory conditions of Euchirograpsus americanus A. Milne Edwards, 1880 (Crustacea, Decapoda: Grapsidae) with notes on Grapsid subfamilial larval characteres. Bull. Mar. Sci. 30 (4): 756-775.

Recebido em 26.VII.1996; aceito em 04.IX.1997. 